\title{
Conidial production by Botryosphaeriaceae species from grapevine shoot lesions in Marlborough vineyards
}

\author{
A. Shafi, H.J. Ridgway, M.V. Jaspers and E.E. Jones \\ Faculty of Agriculture and Life Sciences, Lincoln University, PO Box 85084, Lincoln 7647, \\ New Zealand \\ Corresponding author: Eirian.Jones@lincoln.ac.nz
}

\begin{abstract}
Botryosphaeriaceae species are important pathogens of grapevines so the effect of environmental conditions on sporulation from naturally infected Sauvignon blanc grapevines in two Marlborough vineyards was studied. Shoot lesions characteristic of Botryosphaeriaceae infection were marked on 24 grapevines in each vineyard for observation between September 2014 and April 2015. Pycnidia on the lesions oozed conidia during or soon after rainfall on five occasions at maximum air temperatures of $8.4-19.9^{\circ} \mathrm{C}$ and relative humidities of $77-94.7 \%$. Microscopic observation of the ooze showed conidia characteristic of either Neofusicoccum or Diplodia species in $67 \%$ and $50 \%$ of samples from Vineyard A and B, respectively. Sixtynine colonies characteristic of Botryosphaeriaeae species were recovered after plating of conidial ooze and identified by DNA analysis as Diplodia mutila (39.1\%), Neofusicoccum australe (30.4\%), N. parvum (14.5\%), N. luteum (5.8\%), D. seriata (7.2\%) and N. ribis (3.0\%). All species have been reported previously as grapevine pathogens in New Zealand.
\end{abstract}

Keywords Cirrhi, Neofusicoccum, Diplodia, inoculum production.

\section{INTRODUCTION}

Botryosphaeriaceae species are economically important pathogens on many woody plant hosts worldwide, including grapevines. They cause a range of symptoms, including leaf spots, fruit rots, dieback, perennial cankers, and eventual death of the plants, although symptoms vary according to the host species, cultivar and pathogen species (Alves et al. 2005; Úrbez-Torres et al. 2010). Yield losses caused in vineyards were estimated to be $4-20 \%$ in France and 25-30\% in South Africa (Pearson \& Goheen 1998; Larginon et al. 2001). Together with Eutypa dieback, they were also reported to cause annual losses of over US\$260 million in California, USA (Siebert, 2001) and yield losses of $860 \mathrm{~kg} / \mathrm{ha}$ in Australia (Wicks \& Davis 1999).
In New Zealand, Baskarathevan et al. (2012) reported that the most common Botryosphaeriaceae species isolated from symptomatic grapevine wood tissue were Neofusicoccum parvum, N. luteum, N. australe, Diplodia mutila, Botryosphaeria dothidea and D. seriata, with N. parvum being the predominant species. The same six species were also the most commonly isolated from plants and propagation materials from nine nurseries (Billones-Baaijens et al. 2013). In vineyards, conidia produced on diseased tissue have been reported to be the main inoculum sources, being splash dispersed to infect grapevine tissue through wounds (van Niekerk et al. 2010). Conidia of Botryosphaeriaceae species 
are produced over a wide temperature range $\left(6-30^{\circ} \mathrm{C}\right)$ with maximum sporulation and spore maturation at $18-24^{\circ} \mathrm{C}$ (Copes \& Hendrix 2004). Amponsah et al. (2008) reported that pycnidia and conidial ooze were produced on detached infected green shoots and canes when incubated under high relative humidity $(\mathrm{RH})$ at room temperature, with repeated periods of conidial ooze possible from lesions over a few weeks. For isolates of N. luteum and N. parvum, more conidia were observed to be exuded at higher $(100 \%)$ than lower $\mathrm{RH}(80 \%)$, and at higher $\left(25^{\circ} \mathrm{C}\right)$ than lower $\left(10^{\circ} \mathrm{C}\right)$ temperatures (Shafi 2016). However, artificially inoculated vine material was used in all of these studies and observations from naturally infected material have not been made. Further, although conidia have been detected by trapping in vineyards (Amponsah et al. 2009; Úrbez-Torres et al. 2010; Ridgway et al. 2011; Valencia et al. 2015), observation of cirrhi (a mucus-bound ribbon-like mass extrusion of conidia) from pycnidia on lesions in vineyards has not been reported.

The overall aim of the study was to investigate the effect of environmental conditions on Botryosphaeriaceae sporulation from naturally infected shoots in two Malborough vineyards. This will provide information on the risk period with regards to inoculum production under vineyard conditions.

\section{MATERIALS AND METHODS}

Sauvignon blanc vines within two vineyards (Vineyard A and Vineyard B) in Marlborough, which were known to have infected vines were assessed over a period of 8 months to determine the effects of rainfall on sporulation. In each vineyard, one-year-old shoots with lesions typical of Botryosphaeriaceae species infection (van Niekerk et al. 2006) were marked on 24 randomly distributed vines (one shoot lesion per vine) for ongoing observation. The shoot lesions were observed with a hand lens at $\times 10$ magnification for presence of characteristic pycnidia. Those lesions that produced conidia characteristic of Botryosphaeriaceae species at the first assessment (28 Sept 2014) were observed on four further occasions (10 Dec, $31 \mathrm{Dec}, 6 \mathrm{Mar}$ and 27 Apr) during spring (15 Sept 2014) to winter (4 May 2015) during, or just after rainfall or on dry morning when there had been rain the previous night. At each of these assessments, the same tissues were observed with a hand lens for conidial ooze. To identify the spores, the ooze was removed with a pipette tip, placed on a microscope slide, transported to the laboratory in plastic containers and observed at $\times 100$ with a microscope. When a conidium characteristic of Botryosphaeriaceae species was observed, the slides were washed with a few drops of sterile water $(20 \mu \mathrm{L})$ into a Petri plate containing potato dextrose agar (PDA; Difco ${ }^{\mathrm{TM}}$ ) amended with Triton-X 100 (1 mL/litre; Labchem, Ajax Finechem Pty Ltd) to restrict colony growth and chloramphenicol (0.05 g/litre; Sigma-Aldrich). The liquid was then spread on the surface of the agar with a sterile metal 'hockey stick'. One representative colony characteristic of a Botryosphaeriaceae species was sub-cultured from each isolation plate onto a fresh PDA plate and identified using amplified ribosomal DNA restriction analysis (ARDRA) as described by Alves et al. (2005) and Baskarathevan et al. (2012). To confirm the species determined by ARDRA, sequencing of the ribosomal internally transcribed spacer region (ITS) of randomly selected isolates $(\geq 33 \%)$ was done at the Lincoln University Sequencing facility using an ABI PRISM ${ }^{\circledR} 310$ Genetic Analyser (Applied Biosystems, Foster City, California). The resulting sequences were trimmed using DNAMAN version 4 (Lynnon Biosoft $\left.{ }^{\odot}\right)$. The sequences were compared with those from the NCBI database (www.ncbi.nlm.nih.gov) using Basic Local Alignment Search Tool (BLAST) to confirm species identity.

At the end of the season (4 May 2015), the sections of vine containing the lesions under study were removed from the vineyard. They were transported to the laboratory in separate zip lock bags, where they were washed under tap water and incubated under high relative humidity (100\%) for 3 days at room temperature following the method described by Amponsah et al. (2008). 
However, assessment of conidial numbers could not be conducted because overgrowth by Botryosphaeriaceae mycelium obscured any conidial ooze. Temperature, rainfall and relative humidity data from Marlborough during the periods of observation were obtained from the HortPlus website (http://hortplus.metwatch.co.nz/).

\section{RESULTS}

\section{Release of conidia from naturally infected vines}

During the 8 months when lesions were observed, pycnidia were found oozing five times (Table 1). At the first assessment, conidia characteristic of Botryosphaeriaceae species were observed in the ooze collected from 16 lesions in Vineyard A and 12 lesions in Vineyard B, and only these lesions were continued to be observed for the remainder of the study. On the remaining four assessments, cirrhi of conidia were observed on all the tagged lesions that were positive in the first assessment in both vineyards. The effects of environmental variables [average dew point, leaf wetness, $\mathrm{RH}$, mean air temperature and total rainfall/day] at the time and previous night are shown in Table 2. Ooze from infected canes was collected during, or just after, rainfall and also on dry mornings when there had been rain the previous night. The pycnidia oozed conidia at maximum air temperatures of 8.4 $19.9^{\circ} \mathrm{C}$ and relative humidities of $77.0-94.7 \%$. When the field-collected ooze was observed under the microscope, conidia characteristic of both Neofusicoccum and Diplodia species were observed (Figure 1), with a few samples $(\sim 15 \%$ across both vineyards) containing a mixture of both conidial types.

Table 1 Environmental variables for the previous night and in the morning for the five dates when conidia were seen to ooze from pycnidia on infected canes in Vineyard A and Vineyard B between 15 Sept 2014 and 4 May 2015.

\begin{tabular}{|c|c|c|c|c|c|c|c|c|c|c|}
\hline \multirow[t]{3}{*}{ Environ. variables } & \multicolumn{10}{|c|}{ Dates pycnidia observed to ooze } \\
\hline & \multicolumn{2}{|c|}{$28 \mathrm{Sept}$} & \multicolumn{2}{|c|}{$10 \mathrm{Dec}$} & \multicolumn{2}{|c|}{$31 \mathrm{Dec}$} & \multicolumn{2}{|c|}{$6 \mathrm{Mar}$} & \multicolumn{2}{|c|}{27 Apr } \\
\hline & $\begin{array}{l}\text { Prev. } \\
\text { Night }\end{array}$ & Morn. & $\begin{array}{l}\text { Prev. } \\
\text { Night }\end{array}$ & Morn. & $\begin{array}{l}\text { Prev. } \\
\text { Night }\end{array}$ & Morn. & $\begin{array}{l}\text { Prev. } \\
\text { Night }\end{array}$ & Morn. & $\begin{array}{l}\text { Prev. } \\
\text { Night }\end{array}$ & Morn. \\
\hline Total rain (mm/day) & \multicolumn{2}{|c|}{7.0} & \multicolumn{2}{|c|}{24.8} & \multicolumn{2}{|c|}{10.2} & \multicolumn{2}{|c|}{40.2} & \multicolumn{2}{|c|}{18.1} \\
\hline Max RH (\%) & 93.2 & 86.7 & 82.1 & 90.9 & 79.1 & 81.2 & 77.0 & 91.5 & 94.7 & 90.8 \\
\hline Max. air temp. $\left({ }^{\circ} \mathrm{C}\right)$ & 10.2 & 8.4 & 18.2 & 16.9 & 15.6 & 18.4 & 19.9 & 19.4 & 16.8 & 18.5 \\
\hline
\end{tabular}

Table 2 Neofusicoccum and Diplodia species isolated from conidial ooze recovered from infected canes in Vineyard A (16 lesions) and Vineyard B (12 lesions), Marlborough on specific dates between 15 September 2014 and 4 May 2015.

\begin{tabular}{lcccccccccc}
\hline \multicolumn{1}{c}{} & \multicolumn{7}{c}{ Detection of different Botryosphaeriaceae species } \\
\hline & 28 Sept & \multicolumn{2}{c}{10 Dec } & \multicolumn{2}{c}{31 Dec } & 6 Mar & \multicolumn{2}{c}{27 April } \\
\hline N. luteum & 1 & - & - & - & - & 1 & 2 & - & - & - \\
N. parvum & - & 1 & 2 & 2 & 1 & - & 1 & 2 & 1 & - \\
N. australe & 2 & 3 & 2 & - & - & 3 & 3 & 3 & 3 & 2 \\
D. seriata & - & - & 1 & 2 & - & - & - & - & 1 & 1 \\
D. mutila & 5 & 2 & 4 & 2 & 2 & 1 & 5 & 2 & 3 & 1 \\
N. ribis & - & - & - & - & 1 & 1 & - & - & - & - \\
\hline Total & 8 & 6 & 9 & 6 & 4 & 6 & 11 & 7 & 8 & 4 \\
\hline
\end{tabular}




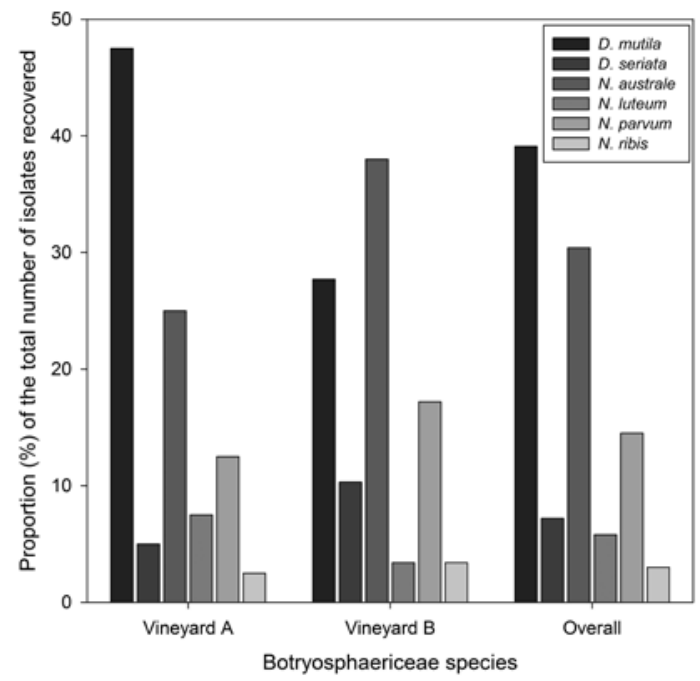

Figure 1 Neofusicoccum and Diplodia species, as a proportion (\%) of the total number colonies, isolated from conidial ooze recovered from infected canes in Vineyard A and Vineyard B, Marlborough between 15 September 2014 and 4 May 2015.

\section{Identification of strains isolated from conidial ooze on shoots in vineyards}

A total of 69 isolates morphologically identified as Botryosphaeriaceae species were recovered from the conidial ooze across both vineyards and assessment times, 40 isolates from Vineyard A and 29 isolates from Vineyard B. Isolates were not recovered into pure culture from all conidial ooze samples due to contamination with other fungi and bacteria. Of the recovered isolates, the frequency of recovered species was D. mutila (39.1\%), N. australe (30.4\%), N. parvum (14.5\%), N. luteum (5.8\%), D. seriata $(7.2 \%)$ and $N$. ribis (3.0\%) (Table 2; Figure 1). At Vineyard A, the predominant species was D. mutila $(47.5 \%)$, followed by $N$. australe (25.0\%), N. parvum (12.5\%), N. luteum (7.5\%), D. seriata (5.0\%) and $N$. ribis (2.5\%). At Vineyard $\mathrm{B}$, the predominant species was $N$. australe (38\%) followed by D. mutila (27.7\%), N. parvum (17.2\%), D. seriata (10.3\%), N. luteum $(3.4 \%)$ and $N$. ribis $(3.4 \%)$.

\section{DISCUSSION}

This is the first report of Botryosphaeriaceae pycnidia on naturally infected grapevine stem lesions observed to produce cirrhi in field conditions. Cirrhi were observed when the morning temperature was as low as $8.4^{\circ} \mathrm{C}$. Alternatively, conidial release might have occurred the previous night when the air temperature was $10.2^{\circ} \mathrm{C}$ or the grapevine tissue could have retained some heat, which could have affected the rate of exudation. These temperatures are similar to, or lower than, the $10^{\circ} \mathrm{C}$ tested in the in vitro study by Shafi (2016). However, Copes \& Hendrix (2004) reported that conidial production by Botryosphaeria dothidea (syn. Fusicoccum aesculi), B. obtusa (syn. Diplodia seriata), and $B$. rhodina (syn. Lasidiplodia theobromae) from inoculated autoclaved apple and pear stems occurred between $6-30^{\circ} \mathrm{C}$, although maximum sporulation was observed at $18-24^{\circ} \mathrm{C}$. No other researchers have reported conidial ooze in the vineyard under natural environmental conditions, probably because the cirrhi, which are exuded in rain conditions, are often removed by rain and rain splash. High relative humidity has also been reported to initiate sporulation by Botryosphaeriaceae spp. (Shafi 2016; Amponsah et al. 2008; Arauz \& Sutton 1989). Van Niekerk et al. (2010) showed that air-borne spores of Diplodia and Dothiorella spp. were present after periods of high relative humidity $(\geq 70 \%)$. Spore-trapping studies in France and New Zealand reported an abundance of Botryosphaeriaceae species spores throughout the year with maximum release being associated with rainfall during summer months (Amponsah et al. 2009; Kuntzmann et al. 2009). Valencia et al. (2015) showed that large numbers of air-borne conidia of Botryosphaeriaceae species were trapped mainly after or during precipitation events of at least $0.2 \mathrm{~mm}$ during autumn and winter, whilst Urbez-Torres et al. (2010) reported release of Botryosphaeriaceae spores after at least $2 \mathrm{~mm}$ of rainfall. In the current study, $7 \mathrm{~mm}$ of rain led to visible oozing of cirrhi in the field, but since the effect of lower levels of rainfall were not assessed the minimum rainfall amount resulting 
in production of cirrhi was not determined.

All species recovered in the sampling of sporulating lesions in both vineyards were isolated from lesions in the previous vineyard sampling (Baskarathevan et al. 2012). Baskarathevan et al. (2012) found that $N$. parvum was the predominant species but this was not the most commonly recovered from conidia exuded from pycnidia on shoot lesions in the current study. Reasons include that this species was not prevalent in the two vineyards sampled, or that this species does not sporulate as profusely as other species. Neofusicoccum ribis, on the other hand, was recovered at low levels from oozing conidia in both vineyards, but Baskarathevan et al. (2012) only recovered this species from vineyards in the Auckland and Nelson regions, and not from Marlborough.

Conidia characteristic of both Neofusicoccum and Diplodia spp. were observed in samples from a few lesions ( $\sim 15 \%$ across both vineyards) although the colonies recovered on agar were of one dominant morphotype in general. This indicated that lesions are typically caused by one Botryosphaeriaceae species, and conidia of other species that were observed may have been splashed from nearby lesions onto the lesions sampled. Multiple species were isolated from single lesions by Baskarathevan et al. (2012) but these isolations were from larger cankers rather than the small shoot lesions in the present study, and so may represent multiple infection events.

The results of this study have shown that Botryosphaeriaceae species ooze cirrhi of conidia over a wide range of temperatures and relative humidities in vineyards and that spore release, and therefore dispersal, is unlikely to be a limiting factor for infection. This is important information for development of control strategies especially in relation to prevention of infection of pruning wounds. Recommendation to growers should include avoiding pruning before and during forecasted rain events to avoid any possible contamination of fresh pruning wounds by rain-splashed conidia. In addition, since wounds can remain susceptible for several weeks (Shafi 2016), fungicides should be applied to protect wounds from any conidia release during any subsequent rain events.

\section{ACKNOWLEDGEMENTS}

The research was funded by Callaghan Innovation and Pernod Ricard. We are grateful to Andrew Naylor (Pernod Ricard) for technical advice and the vineyard managers for access to vineyards.

\section{REFERENCES}

Alves A, Phillips AJL, Henriques I, Correia A 2005. Evaluation of amplified ribosomal DNA restriction analysis as a method for the identification of Botryosphaeria species. FEMS Microbiology Letters 245 (2): 221-229. Amponsah NT, Jones EE, Ridgway HJ, Jaspers MV 2008. Production of Botryosphaeria species conidia using grapevine green shoots. New Zealand Plant Protection 61: 301-305.

Amponsah NT, Jones EE, Ridgway HJ, Jaspers MV 2009. Rainwater dispersal of Botryosphaeria conidia from infected grapevines. New Zealand Plant Protection 62: 228-233.

Arauz LF, Sutton TB 1989. Influence of temperature and moisture on germination of ascospores and conidia of Botryosphaeria obtusa. Phytopathology 79: 667-674.

Baskarathevan J, Jaspers MV, Jones EE, Ridgway HJ 2012. Identification, incidence and distribution of botryosphaeriaceous species in New Zealand vineyards. European Journal of Plant Pathology 132: 549-560.

Billones-Baaijens R, Ridgway HJ, Jones EE, Cruickshank RH, Jaspers MV 2013. Prevalence and distribution of Botryosphaeriaceae species in New Zealand grapevine nurseries. European Journal of Plant Pathology 135: 175-185.

Copes WE, Hendrix Jr-FF 2004. Effect of temperature on sporulation of Botryosphaeria dothidea, B. obtusa, and B. rhodina. Plant Disease 88: 292-296.

Kuntzmann P, Villaume S, Bertsch C 2009. Conidia dispersal of Diplodia species in a French vineyard. Phytopathologia Mediterranea 48: 150-154. 
Larignon P, Fulchic R, Cere L, Dubos B 2001. Observations on black dead arm in French vineyards. Phytopathologia Mediterranea 40: S336-S342.

Pearson RC, Goheen AC 1988. Compendium of Grape Diseases. American Phytopathological Society pp 93.

Ridgway HJ, Amponsah NT, Dore D, Baskarathevan J, Jones EE, Jaspers MV 2011. Detection of botryosphaeriaceous species in environmental samples using a multi-species primer pair. Plant Pathology 60: 1118-1127.

Shafi A 2016. Botryosphaeria dieback in vineyards: conidial dispersal, infection, disease development and control. Lincoln University, Lincoln, New Zealand, PhD thesis.

Siebert JB 2001. Eutypa: The economic toll on vineyards. Wines Vines (April) 50: 56.

Úrbez-Torres JR, Battany M, Bettiga LJ, Gispert C, McGourty G, Roncoroni J, Gubler WD 2010. Botryosphaeriaceae species spore-trapping studies in California vineyards. Plant Disease 94: 717-724.
Valencia D, Torres C, Camps R, López E, CelisDiez JL, Besoain X 2015. Dissemination of Botryosphaeriaceae conidia in vineyards in the semiarid Mediterranean climate of the Valparaíso Region of Chile. Phytopathologia Mediterranea 54: 394-402.

van Niekerk JM, Fourie PH, Halleen F, Crous PW 2006. Botryosphaeria spp. as grapevine trunk disease pathogens. Phytopathologia Mediterranea 45: S43-S54.

van Niekerk JM, Calitz FJ, Halleen F, Fourie PH 2010. Temporal spore dispersal patterns of grapevine trunk pathogens in South Africa. European Journal of Plant Pathology 127: 375-390.

Wicks T, Davies K 1999. The effect of Eutypa on grapevine yield. Australian Grapegrower and Winemaker 426: 15-16. 